\title{
Gynecomastia in multi-drug resistant tuberculosis ethionamide the villain
}

\author{
Kunal Deokar', Abdul Latif Shaikh', Gopal Chawla² \\ 'Government Medical College and Hospital, Miraj, Maharashtra, India \\ ${ }^{2}$ Government Medical College, Patiala, Punjab, India
}

A 59-year-old married male, a known case of line probe assay-confirmed multidrug-resistant pulmonary tuberculosis was treated with kanamycin, levofloxacin, ethionamide, ethambutol, pyrazinamide and cycloserine for seven months. He was responding to treatment, had gained five kg weight and underwent culture conversion. He presented with painful swelling of both the breasts for 15 days. It was not associated with nipple bleeding or discharge. There was no history of any other drug intake. $3.5 \mathrm{~cm}$ and $3 \mathrm{~cm}$ single, tender, firm nodule concentric with nipple-areolar complex could be palpated in the right and left breasts, respectively (Figure 1). It was not associated with skin dimpling or nipple retraction. On examination, thyroid, external genitalia and secondary sexual characters were normal. Bilateral breast ultrasound revealed glandular tissue hyperplasia. Ultrasound of the abdomen and scrotum was normal. Liver and kidney function tests revealed no abnormality. His serum was non-reactive for HIV-1 and HIV-2 by ELISA. Serum TSH was $1.86 \mu \mathrm{IU} / \mathrm{mL}(0.3-5.5 \mu \mathrm{IU} / \mathrm{mL})$, serum testosterone was $302.6 \mathrm{ng} / \mathrm{dL}$ (241-827 ng/dL), serum estradiol was $38.4 \mathrm{pg} / \mathrm{mL}$ (0-39.8 pg/mL). Computed tomography of the adrenals showed no abnormality. Ethionamide was suspected to be the cause of gynecomastia and was stopped and replaced by para-aminosalicylic acid. His breast swelling resolved slowly within 1 month after stopping ethionamide. Thus, a clinical diagnosis of ethionamide-induced gynecomastia was made. As per the World Health Organization (WHO) Uppsala monitoring center causality assessment scale[1], the present adverse reaction is probable/likely associated with ethionamide.

Gynecomastia is enlargement of male breast glandular tissue. Drugs are responsible for $10-25 \%$ of cases of gynecomastia. Drugs which are known to cause gynecomastia include spironolactone, ketoconazole, cimetidine, estrogen preparations, 5 - $\alpha$ reductase inhibitors, human chorionic gonadotropin, human growth hormone, gonadotropin releasing hormone (GnRH) analogs, risperidone, omeprazole, nifedipine, verapamil, efavirenz. Anti-tubercular drugs implicated to cause gynecomastia include isoniazid, ethionamide and thioacetazone [2-3]. Ethionamide is used for treatment of drug-resistant tuberculosis. The mechanism by which it causes gynecomastia is not known. PubMed search using MeSH terms "Ethionamide”, "Gynecomastia” revealed only two case reports (Table 1).
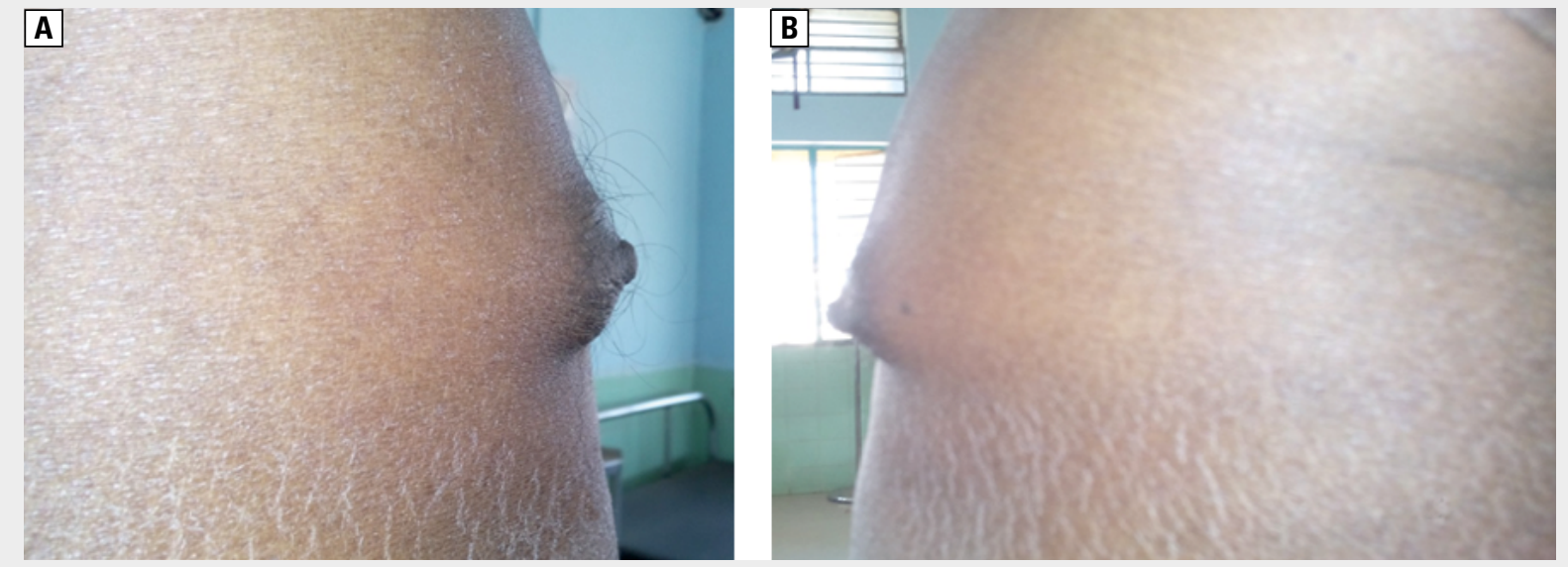

Figure 1. Lateral view of enlarged right breast and enlarged left breast

Address for correspondence: Gopal Chawla, Government Medical College, Patiala, Patiala, Punjab, India; e-mail: dr.gopalchawla@gmail.com DOI: 10.5603/ARM.2020.0093

Received: 21.11.2019

Copyright (C) 2020 PTChP

ISSN 2451-4934

Conflict of interest: none declared 
Table 1. Case reports of ethionamide- induced gynecomastia

\begin{tabular}{lcccccc}
\hline Author & Year & $\begin{array}{c}\text { Age of patient } \\
\text { in years }\end{array}$ & $\begin{array}{c}\text { Range of onset } \\
\text { after starting } \\
\text { suspected drug }\end{array}$ & De-challenge & Re-challenge & Sex hormones \\
\hline Dixit et al. [3] & 2012 & 38 & 2 months & Yes & Yes & Normal \\
Sharma et al. [4] & 2012 & 43 & 4 months & Yes & No & Not done \\
Present case & 2019 & 59 & 7 months & Yes & No & Normal \\
\hline
\end{tabular}

Points which favor ethionamide-induced gynecomastia in our patient include: 1 . Temporal association recent onset of gynecomastia while the patient was taking anti-tuberculosis drugs; 2 . Ethionamide is known to cause gynecomastia; 3. Exclusion of other causes: there was no history of any other drug intake. Normal biochemical and endocrinological investigations; 4. Dechallenge - gynecomastia disappeared after stopping ethionamide. Gynecomastia in our patient on the WHO Uppsala monitoring center causality assessment scale [3] is probable/likely associated with ethionamide.

Thus, our case report emphasizes the fact that ethionamide can cause painful gynecomastia and clinicians must be aware of this adverse event. In view of the frequent adverse events of second-line anti-tuberculosis drugs, implementation of pharmacovigilance and monitoring of adverse events (aDSM) have been recommended by WHO. Furthermore, a team approach to the management of adverse events known as Tuberculosis Consilium has shown to be useful [5].

\section{References:}

1. The use of the WHO-UMC system for standardized case causality assessment. Accessed from: www.who.int/medicines/areas/quality_safety/safety_efficacy/WHOcausality_assessment.pdf. [Access: 20.05.2019].

2. Deepinder F, Braunstein GD. Drug-induced gynecomastia: an evidence-based review. Expert Opin Drug Saf. 2012; 11(5): 779-795, doi: 10.1517/14740338.2012.712109, indexed in Pubmed: 22862307.

3. Dixit R, George J, Sharma AK, et al. Ethionamide-induced gynecomastia. J Pharmacol Pharmacother. 2012; 3(2): 196-199, doi: 10.4103/0976-500X.95532, indexed in Pubmed: 22629101.

4. Sharma PK, Bansal R. Gynecomastia caused by ethionamide. Indian J Pharmacol. 2012; 44(5): 654-655, doi: 10.4103/02537613.100408, indexed in Pubmed: 23112434.

5. Tiberi S, Pontali E, Tadolini M, et al. Challenging MDR-TB clinical problems. The case for a new Global TB Consilium supporting the compassionate use of new anti-TB drugs. Int J Infect Dis. 2019; 80S: S68-S72, doi: 10.1016/j.ijid.2019.01.040, indexed in Pubmed: 30690212 . 